\title{
BMJ Open Proton pump inhibitor utilisation and potentially inappropriate prescribing analysis: insights from a single-centred retrospective study
}

\author{
Yujuan Liu (D) , ${ }^{1}$ Xian Zhu, ${ }^{2}$ Rongxin Li, ${ }^{2}$ Jun Zhang, ${ }^{1}$ Feng Zhang ${ }^{2}$
}

To cite: Liu Y, Zhu X, Li R, et al. Proton pump inhibitor utilisation and potentially inappropriate prescribing analysis: insights from a single-centred retrospective study. BMJ Open 2020;10:e040473. doi:10.1136/ bmjopen-2020-040473

- Prepublication history and supplemental material for this paper is available online. To view these files, please visit the journal online (http://dx.doi. org/10.1136/bmjopen-2020040473).

Received 15 May 2020

Revised 10 September 2020

Accepted 30 September 2020

Check for updates

(C) Author(s) (or their employer(s)) 2020. Re-use permitted under CC BY-NC. No commercial re-use. See rights and permissions. Published by BMJ.

${ }^{1}$ Clinical Pharmacy Department, Jinshan Hospital Affiliated to Fudan University, Shanghai, China

${ }^{2}$ Emergency Department, Jinshan Hospital Affiliated to Fudan University, Shanghai, China

Correspondence to

Dr Feng Zhang; jgyyzf@126.com

\section{ABSTRACT}

Objectives This study aimed to characterise the prescribing patterns and evaluate the appropriateness of the prescribed proton pump inhibitors (PPIs) in adult patients via a review of electronic medical records in a single-centred hospital.

Design All patients admitted to the outpatient department of Jinshan Hospital, Fudan University, Shanghai, between 1 January 2018 and 31 December 2018 were evaluated. Individuals aged 18 years or above and with at least one dispensing for PPIs were identified as PPI users. New PPI users were defined as a subject who did not receive any dispensing for PPIs in the year prior to the index date. Baseline characteristics of PPI users and their therapies were described by treatment indication, economic indicators and co-prescription, overall and separately.

Setting The prescription database was retrieved from the hospital information system of Jinshan Hospital, Fudan University.

Results Among 18435 identified PPI users in 2018, 14219 patients (aged 18 years or above) who had at least one dispensing PPIs were new users (77\%), and among them, men accounted for $47 \%$. The mean treatment duration was 23 days. Omeprazole was the most commonly prescribed drug. PPIs are inappropriately prescribed in 50\% (13589/25 850) of prescriptions. Prescription appropriateness analysis indicated that the unapproved indications for PPI new users accounted for $47 \%$; among them, the proportion of gastritis diagnosis was $34 \%$. The proportion of PPI new users with coprescription of glucocorticosteroids (GCs) who have risk factors accounted for $24 \%$ and lower than other co-prescription. A majority of PPI users (73\%) reported high-dose PPI prescription. The defined daily dose of oral pantoprazole was the highest, and injectable omeprazole had the highest defined daily cost. In contrast, only the drug utilisation index value of oral esomeprazole was less than 1.0.

Conclusion The results indicate the challenge of PPI use was accompanied by unapproved indications, frequent inappropriate co-prescription with GCs and excessive dosages. Efforts should be paid to promote rational use and ensure the choice of suitable PPI therapy in the future.

\section{Strengths and limitations of this study}

- This is the most recent and comprehensive study on proton pump inhibitor (PPI) utilisation based on data from a big third-tier hospital to reflect the trends and general problems in PPI usage.

- The study covered multifaceted information on PPIs including different types, dispensing frequency, duration, prophylactic use, defined daily dose, defined daily cost and drug utilisation index values, and dose intensity which would provide a comprehensive view for PPI usage in clinical practice.

- Appropriateness of PPI usage was also evaluated and discussed.

- The study lacks comparison with other prehospital systems and follow-up data on evaluation after the intervention.

- This is a cross-sectional study with small sample size and did not include the data from the private healthcare and community hospitals; further randomised clinical trials may be needed to provide causative explanations.

\section{INTRODUCTION}

Proton pump inhibitors (PPIs) are essentially $\mathrm{H}^{+}-\mathrm{K}^{+}$-ATPase inhibitors suppressing gastric acid secretion. These drugs tend to be used for the management of acid-related diseases, such as peptic ulcer disease (PUD), gastro-oesophageal reflux disease (GORD), gastrointestinal (GI) bleeding and Helicobacter pylori infection, or the prevention of gastric ulcers in patients who are taking nonsteroidal anti-inflammatory drugs (NSAIDs), glucocorticosteroids (GCs), antiplatelet and anticoagulants. ${ }^{1}$

The currently marketed main PPIs include omeprazole, esomeprazole, lansoprazole, pantoprazole and rabeprazole. PPI usage has dramatically increased since the introduction in the late 1980s. Nowadays, they have become one of the most commonly prescribed and used drugs in the world. ${ }^{2}$ For instance, in the UK, nearly 59 million PPIs 
were dispensed annually, and the total usage doubled since 2007. ${ }^{3}$ In one of the largest teaching hospitals in the southwest of China, an appreciable increase in PPI utilisation was observed rising about 10.4-fold between 2004 and 2013. ${ }^{4}$ Meanwhile, urgent concern about the overutilisation of PPIs has been growing. It has been estimated that between $25 \%$ and $70 \%$ of the PPI prescriptions in the USA have no appropriate indication. ${ }^{25}$ What is more, PPIs have recently been associated with a variety of severe adverse effects such as osteoporosis and associated fractures, hypomagnesemia, community-acquired pneumonia, Clostridium difficile colitis and cardiovascular morbidity. ${ }^{6-11}$

Even though extensive studies have been investigated on the appropriateness of PPIs in Western countries, such data from China are still very limited. Thus, there is an urgent need to characterise the prescribing patterns and drug utilisation research, and to evaluate the appropriateness of the initiative of prescribing PPIs, so that rationality and cost-effectiveness could be improved in the future.

\section{METHODS}

\section{Data source and sample selection}

Electronic medical records were retrieved from the hospital information system of Jinshan Hospital Affiliated to Fudan University. The prescription contains the medical card number, prescription number, age, gender, diagnosis (based on the International Classification of Diseases 10th edition), the specialty of the primary prescriber, generic name of PPIs and dosage. Individuals aged 18 years or above in outpatient service with at least one dispensing for PPIs in 2018 were identified as PPI users and were included in the study. The first dispensing date for PPIs was defined as the index date. PPI users were defined as new users if they did not receive any dispensing for PPIs in the year prior to the index date. We excluded patients with a missing medical card number or an unknown date of birth or gender and patients who changed their prescribed PPIs in a calendar year.

\section{Different types of PPIs and frequency of dispensing}

Different types of PPIs including omeprazole $(10 \mathrm{mg}$, $20 \mathrm{mg}$ ), esomeprazole $(20 \mathrm{mg})$, lansoprazole ( $15 \mathrm{mg}$, $30 \mathrm{mg}$ ), pantoprazole $(40 \mathrm{mg})$ and rabeprazole $(20 \mathrm{mg})$ prescription were analysed. Patients were deemed to be prescribed PPIs once when they received any type and dosage of PPIs. The frequency of dispensing was evaluated according to the prescription dates.

\section{Duration of PPI prescription}

We defined treatment duration by the number of PPI tablets dispensed. Treatment discontinuation was confirmed by the absence of a new prescription within the estimated dispensing duration plus a 30-day grace period. Treatment duration was categorised as less than a month, 1-3 months, 3-6 months and more than 6 months. PPI users after the initial prescription lasting more than 6 months were considered as long-term users.

\section{Prophylactic use of PPIs}

First, PPI co-prescription included NSAID therapy, antiplatelet therapy, anticoagulant therapy and GC therapy for the prevention of gastric ulcers in the survey. Then, based on PPI co-prescription, recommendations for PPI prophylaxis should include at least one risk factor: (1) age $>65$ years, (2) antiplatelet/NSAID/anticoagulant/ GCs use and (3) history of peptic ulcer disease.

\section{DDD, DDC and DUI values of different PPIs}

Drug utilisation research was assessed using the prescription number, proportion and economic indicators. The defined daily dose (DDD) value for PPIs including oral or injectable form was the assumed average dose advocated by WHO. The defined daily cost (DDC) value was calculated by the total sales of PPIs (China yuan) divided by the DDD value, whereas the drug utilisation index (DUI) value was described as the ratio of the DDD value and the actual days of PPI use. To evaluate the rationality of PPI use, DUI values exceeding 1.0 indicate the existence of inappropriate use.

\section{PPI DOSE INTENSITY}

Low dose, standard and high dose were categorised as per definition referred to ${ }^{12}$ and DDD value (as shown in table 1). If the product dose was equal to and higher than the DDD, it was distinguished as standard and high dose; otherwise, it was classified as low dose.

\section{Pattern of prescription and definition of appropriateness}

The pattern of prescription was evaluated by types of PPIs and frequency of dispensing, duration and prophylactic use of PPIs, drug utilisation research (DDD, DDC

\begin{tabular}{llllll}
\hline \multicolumn{7}{l}{ Table 1} & Definition of low-dose, standard and high-dose proton pump inhibitors (PPIs) & & \\
\hline PPIs & & & & & \\
\hline Dose & Esomeprazole & Lansoprazole & Omeprazole & Pantoprazole & Rabeprazole \\
\hline Low dose $(\mathrm{mg})$ & NA & $\leq 15$ & $\leq 10$ & $\leq 20$ & $\leq 10$ \\
Standard dose $(\mathrm{mg})$ & 20 & 30 & 20 & 40 & 20 \\
High dose $(\mathrm{mg})$ & $>20$ & $>30$ & $>20$ & $>40$ & $>20$ \\
\hline
\end{tabular}

NA, not applicable. 
and DUI) and dose intensity. A prescription was deemed appropriate in case (1) the approved indications were defined as PUD, GORD, GI bleeding and $H$. pylori infection; (2) the duration of therapy was $4-8$ weeks following the diagnosis of PUD, 4-8 weeks for GORD, 6-8 weeks for GI bleeding or 2 weeks for $H$. pylori infection according to the most recent recommendations of the Expert consensus on optimal application of PPIs ${ }^{13}$ and Expert consensus on the rational use of PPIs in the elderly in China ${ }^{14}$; and (3) prophylactic use of PPIs meets the condition defined previously.

\section{Statistical analysis}

The demographic and clinical characteristics of patients were summarised by descriptive statistics. Categorical variables including frequency and percentage were described across all respondents and evaluated using the $\chi^{2}$ or Fisher's exact test as appropriate. Continuous variables were expressed as mean $\pm \mathrm{SD}$ or as median and range, and were compared using Student's t-test (two groups) or one-way ANOVA. Differences were considered statistically significant when $\mathrm{p}$ values were less than 0.05 .

\section{Patient and public involvement}

We did not directly involve patients or the public in our study.

\section{RESULTS}

\section{Patient characteristics}

The total number of outpatient visits during the year of study was 1281769 . We identified 18435 PPI users (from 38076 prescriptions) and 14219 new users (from 25850 prescriptions) ( $47 \%$ men, $53 \%$ women, men vs women: $0.9 / 1.0$ ), which accounted for $3.0 \%$ and $2.0 \%$ of all outpatient visits, respectively. Groups aged between 18 and 65 years reached up to $84 \%$ (11 921/14 219) (table 2). There was a significant difference in gender across the two age groups $(\mathrm{p}<0.05)$. Patients' prescriptions were mostly from the Department of Gastroenterology (82\%) and General Internal Medicine (10\%).

\section{Types, frequency and duration of PPIs}

Among all new users, omeprazole was the most frequently dispensed PPI at initiation (33\%) followed by rabeprazole $(31 \%)$ and pantoprazole $(27 \%)$. Omeprazole accounts for $38 \%$ of new users aged $>65$ years. There were differences in the proportion of patients in the two age groups using different drugs $(\mathrm{p}<0.05)$. The average number of dispensing was $1.8( \pm 1.5)$, and $59 \%$ of new users received only one dispensing. In contrast, $12 \%$ of new users in the group aged $>65$ years received four or more dispensing $(\mathrm{p}<0.05)$.

The duration of PPIs was divided into four categories: less than 1 month (83\%), 1-3 months (14\%), 3-6 months $(2.0 \%)$ and more than 6 months $(0.4 \%)$. The mean treatment duration was 23 days and was higher among the group aged $>65$ years than that among those aged 18-65

\begin{tabular}{|c|c|c|c|}
\hline & $\begin{array}{l}\text { Overall } \\
(n=14219) \\
n(\%)\end{array}$ & $\begin{array}{l}18-65 \text { years } \\
(n=11921) \\
n(\%)\end{array}$ & $\begin{array}{l}>65 \text { years } \\
(n=2298) \\
n(\%)\end{array}$ \\
\hline \multicolumn{4}{|l|}{ Sex } \\
\hline Male & $6717(47)$ & $5728(48)$ & $989(43)$ \\
\hline Female & 7502 (53) & $6193(52)$ & $1309(57)$ \\
\hline Age, years, mean (SD) & 49 (15) & $45(12)$ & $73(6.2)$ \\
\hline \multicolumn{4}{|l|}{$\begin{array}{l}\text { Characteristics of PPI } \\
\text { therapy }\end{array}$} \\
\hline Omeprazole & $4661(33)$ & 3792 (32) & $869(38)$ \\
\hline Rabeprazole & 4356 (31) & $3720(31)$ & $636(28)$ \\
\hline Esomeprazole & $277(2.0)$ & $198(1.7)$ & $79(3.4)$ \\
\hline Pantoprazole & $3853(27)$ & $3296(28)$ & $557(24)$ \\
\hline Lansoprazole & $1072(7.6)$ & $915(7.7)$ & $157(6.8)$ \\
\hline \multicolumn{4}{|l|}{ No of PPI dispensing } \\
\hline Mean (SD) & $1.8(1.5)$ & $1.8(1.5)$ & $2.0(1.9)$ \\
\hline 1 & 8443 (59) & $7128(60)$ & $1315(57)$ \\
\hline 2 & $3291(23)$ & $2811(24)$ & $490(21)$ \\
\hline 3 & $1235(8.7)$ & $1012(8.5)$ & $223(9.7)$ \\
\hline 4 or more & $1250(8.8)$ & $970(8.1)$ & $280(12)$ \\
\hline \multicolumn{4}{|l|}{ Treatment duration } \\
\hline Mean (SD), days & $23(24)$ & $22(22)$ & $28(32)$ \\
\hline $0-1$ month & $11859(83)$ & $10079(85)$ & 1795 (78) \\
\hline $1-3$ months & $2020(14)$ & $1603(13)$ & $402(17)$ \\
\hline $3-6$ months & $281(2.0)$ & $201(1.7)$ & $80(3.5)$ \\
\hline More than 6 months & $60(0.4)$ & $37(0.3)$ & $23(1.0)$ \\
\hline
\end{tabular}

years (28 days vs 22 days). PPI therapy prolonged $>6$ months accounted for $0.4 \%$ of new users and was higher in the group aged $>65$ years when compared with the group aged $18-65$ years $(1.0 \%$ vs $0.3 \%)$. In terms of duration for approved indication, duration within 1 month accounted for the majority, while the PPIs used for long term ( $>6$ months) were very few (online supplemental table S1).

\section{Clinical diagnosis for PPI prescriptions}

From the total 25850 PPI prescriptions in 2018, the approved indications for PPI new users included $H$. pylori eradication (34\%), PUD $(9.3 \%)$, GORD $(5.5 \%)$ and GI bleeding $(0.8 \%)$ (figure 1$)$. Moreover, the PPI prescriptions with a diagnosis of gastritis-related and dyspepsia accounted for $34 \%$ and $1.0 \%$, respectively. Pantoprazole was the primarily used PPI to treat the preceding approved indications $(39 \%)$, followed by rabeprazole $(32 \%)$, omeprazole $(19 \%)$, lansoprazole $(6.9 \%)$ and esomeprazole $(2.5 \%)$.

\section{Characteristics of co-prescription}

The co-prescription with GCs accounted for the majority $(\mathrm{n}=314,2.2 \%)$ (table 3$)$. The average age of PPI users with co-prescription of GCs $(49 \pm 17)$ was significantly smaller than co-prescription with antiplatelet drugs $(67 \pm 13)$ 


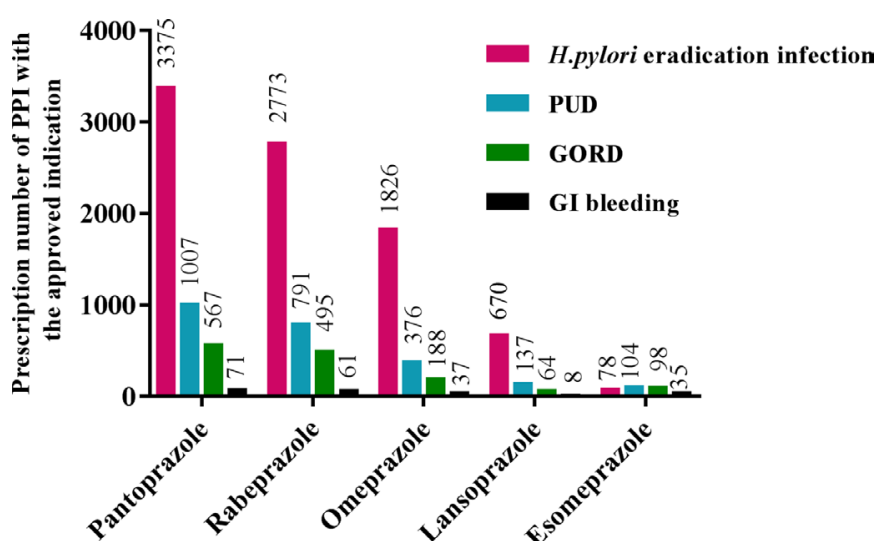

Figure 1 Prescription number of different proton pump inhibitors (PPIs) with approved indications. GORD, gastrooesophageal reflux disease; Gl, gastrointestinal; PUD, peptic ulcer disease.

$(\mathrm{p}<0.05)$. Among the commonly used PPIs with co-prescription of antiplatelet, NSAID and GC therapy, omeprazole was the most commonly prescribed (figure 2). In contrast, pantoprazole was mainly used in combination with anticoagulant drugs.

The average number of dispensing with co-prescription of NSAID was 1.1, and a large proportion $(90 \%)$ of the prescriptions contained only one dispensing $(p<0.05)$. A higher dispensing rate was observed among PPI new users

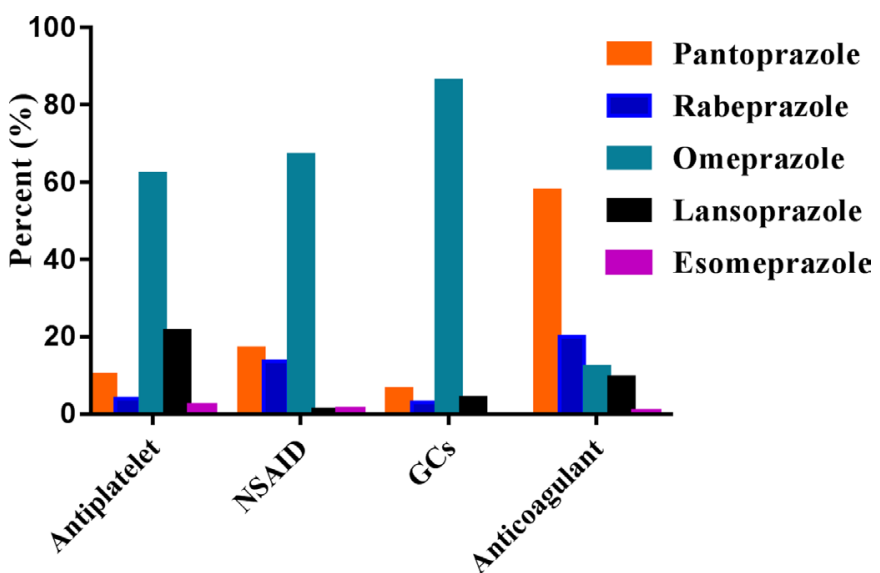

Figure 2 Percentage of different proton pump inhibitors among the co-prescription drugs. GC, glucocorticosteroid; NSAID, non-steroidal anti-inflammatory drug.

with co-prescription of anticoagulant (1.8). In addition, we found over four dispensing with co-prescription of GCs and anticoagulants, which accounted for $10.19 \%$ and $12 \%$ of all PPI new users, respectively. The shortest mean treatment duration (17 days) was observed in co-prescription with NSAID. Only a few patients among PPI co-prescription users were treated with PPIs for more than 3 months $(\mathrm{p}>0.05)$.

Table 3 Characteristics of new proton pump inhibitor (PPI) users with co-prescription of antiplatelet, NSAID, GCs and anticoagulant

\begin{tabular}{|lllll}
\hline & $\begin{array}{l}\text { Co-prescription } \\
\text { with antiplatelet } \\
\text { (N=71) }\end{array}$ & $\begin{array}{l}\text { Co-prescription } \\
\text { with NSAID } \\
\text { (N=80) }\end{array}$ & $\begin{array}{l}\text { Co-prescription } \\
\text { with GCs } \\
\text { (N=314) }\end{array}$ & $\begin{array}{l}\text { Co-prescription } \\
\text { with anticoagulant } \\
\text { (N=106) }\end{array}$ \\
\hline $\begin{array}{l}\text { Sociodemographic characteristics } \\
\text { Men }\end{array}$ & $39(55)$ & $37(46)$ & $149(47)$ & $33(31)$ \\
\hline Women & $32(45)$ & $43(54)$ & $165(53)$ & $73(69)$ \\
\hline Age, years, mean & $67 \pm 13$ & $54 \pm 18$ & $49 \pm 17$ & $66 \pm 12$ \\
\hline 18-65years & $28(39)$ & $59(74)$ & $254(81)$ & $46(43)$ \\
\hline$>65$ years & $43(61)$ & $21(26)$ & $60(19)$ & $60(57)$ \\
No of PPI dispensing & & & & $1.8(1.9)$ \\
\hline Mean (SD) & $1.4(0.7)$ & $1.1(0.3)$ & $1.7(1.7)$ & $76(71)$ \\
\hline 1 & $50(70)$ & $72(90)$ & $230(73)$ & $11(10)$ \\
\hline 2 & $15(21)$ & $8(10)$ & $39(12)$ & $6(5.7)$ \\
\hline 3 & $3(4.2)$ & $0(0.0)$ & $13(4.1)$ & $13(12)$ \\
\hline 4 or more & $3(4.2)$ & $0(0.0)$ & $32(10)$ & $27.63(29)$ \\
Treatment duration & & & & $85(80)$ \\
\hline Mean (SD) (days) & $25.63(19)$ & $16.63(10)$ & $27.65(35)$ & $14(13)$ \\
\hline 0-1 month & $57(80)$ & $75(94)$ & $245(78)$ & $6(5.7)$ \\
\hline 1-3 months & $13(18)$ & $5(6.3)$ & $55(18)$ & $1(0.9)$ \\
\hline 3-6 months & $1(1.4)$ & $0(0.0)$ & $9(2.9)$ & $5(1.6)$ \\
\hline More than 6 months & $0(0.0)$ & $0(0.0)$ & & \\
\hline
\end{tabular}

GC, glucocorticosteroid; NSAID, non-steroidal anti-inflammatory drug. 


\begin{tabular}{|c|c|c|c|c|c|c|c|}
\hline PPIs & $\begin{array}{l}\text { DDD } \\
(\mathrm{mg})\end{array}$ & $\begin{array}{l}\text { Total sales } \\
\text { (yuan) }\end{array}$ & $\begin{array}{l}\text { Total doses } \\
(\mathrm{mg})\end{array}$ & $\begin{array}{l}\text { Medication } \\
\text { days }\end{array}$ & $\begin{array}{l}\text { DDD } \\
(\mathrm{mg})\end{array}$ & $\begin{array}{l}\text { DDC } \\
\text { (yuan) }\end{array}$ & DUI \\
\hline Oral esomeprazole & 30 & 91564 & 185360 & 7221 & 6178.67 & 15 & 0.9 \\
\hline Oral lansoprazole & 30 & 136973 & 1134630 & 23142 & 37281 & 3.6 & 1.6 \\
\hline Injectable omeprazole & 40 & 6252 & 7720 & 184 & 193 & 32 & 1.1 \\
\hline
\end{tabular}

DDC, defined daily cost; DDD, defined daily dose; DUI, drug utilisation index; PPI, proton pump inhibitor.

\section{DDDs, DDC and DUI values of different PPIs}

We analysed the DDDs, DDC and DUI values of different PPIs. Table 4 shows that the DDD value of oral pantoprazole was the highest, while the lowest DDD value was observed in injectable omeprazole. The minimum value of DDC was obtained in oral lansoprazole. Only the DUI value of oral esomeprazole was less than 1.0, and the DUI value of oral pantoprazole was the highest (1.8).

\section{PPI intensity utilisation patterns}

The high-dose PPI prescription comprises the majority $(73 \%)$ (table 5). The high dose of lansoprazole, rabeprazole and pantoprazole accounted for $78 \%, 69 \%$ and $81 \%$, respectively. In contrast, the standard dose of esomeprazole accounted for $63 \%$, followed by rabeprazole (31\%). The low dose of total PPI prescription accounted for $3.6 \%$.

\section{Assessment of PPIs appropriateness}

Overall, PPIs are inappropriately prescribed in 50\% (13 $589 / 25850$ ) of prescriptions. In order to reveal the main categories of inappropriate drug use, PPI appropriateness was further evaluated by the approved indications, the duration of therapy for different diseases and prophylactic use of PPIs, respectively. In detail, the rate of appropriateness according to the approved indications was $53 \%$. In contrast, a high rate of appropriate prescriptions was observed for the duration (PUD: 99.6\%, GORD: 99.7\%, H. pylori eradication: $95.3 \%$ and GI bleeding: $99.5 \%$ ).

Table 5 Proton pump inhibitor (PPI) intensity utilisation patterns according to different PPI prescriptions

\begin{tabular}{lccr}
\hline & \multicolumn{3}{l}{ Total daily dose of PPIs } \\
\cline { 2 - 4 } PPIs & Low dose & Standard dose & High dose \\
\hline Omeprazole & $823(12)$ & $1303(19)$ & $4870(70)$ \\
Esomeprazole & - & $366(63)$ & $215(37)$ \\
Lansoprazole & $105(6.0)$ & $283(16)$ & $1370(78)$ \\
Rabeprazole & - & $2376(31)$ & $5366(69)$ \\
Pantoprazole & - & $1631(19)$ & $7142(81)$ \\
Sum & $928(3.6)$ & $5959(23)$ & $18963(73)$ \\
\hline
\end{tabular}

'-': not available.
According to the recommendations for PPI prophylaxis, the proportion of PPI new users with co-prescription of GCs who have risk factors was lower when compared with that of anticoagulant ( $24 \%$ vs $91 \%$ ), while the proportions of PPI new users with co-prescription of NSAID was $43 \%$ (table 6 ).

\section{DISCUSSION}

Based on hospital electronic medical records data, our study provides important insights into the patterns of utilisation among new PPI users. We found that $3.0 \%$ of outpatient visits were PPI users, and $77 \%$ of them were new users. Given that PPIs are the most frequently used drugs worldwide, its overutilisation has become more common in recent years. For example, in one study from the USA, PPIs were prescribed in $4 \%$ of outpatient visits in 2002 and increased to $9.2 \%$ in $2009 .{ }^{15}$ Besides, similar increases in prescription rates have also been observed in many other countries. ${ }^{16-19}$ Although our result revealed

Table 6 Number and proportion of appropriate PPI prescriptions

\begin{tabular}{lrr}
\hline & \multicolumn{2}{c}{ Appropriate PPI prescription } \\
\cline { 2 - 3 } Category & Yes (100\%) & No (100\%) \\
\hline Approved indication & $13713(53)$ & $12137(47)$ \\
Duration & & \\
\multicolumn{1}{c}{ PUD } & $2405(99.6)$ & $10(0.4)$ \\
\multicolumn{1}{c}{ GORD } & $1409(99.7)$ & $4(0.3)$ \\
H. pylori eradication & $8310(95.3)$ & $412(4.7)$ \\
\hline GI bleeding & $211(99.5)$ & $1(0.5)$ \\
Co-prescription & & \\
Antiplatelet & $48(68)$ & $23(32)$ \\
NSAID & $34(43)$ & $46(57)$ \\
GCs & $76(24)$ & $238(76)$ \\
Anticoagulant & $96(91)$ & $10(9)$ \\
\hline
\end{tabular}

GC, glucocorticosteroid; GI, gastrointestinal; GORD, gastrooesophageal reflux disease; NSAID, non-steroidal antiinflammatory drug; PPI, proton pump inhibitor; PUD, peptic ulcer disease. 
that the prevalence of PPI use was less than that of other reports, an appreciable increase in PPI utilisation has been witnessed in other regions in China ${ }^{20}$ which could be reflected in a study conducted, in particular, for injectable PPIs. ${ }^{4}$ These facts pose serious queries and concerns on the inappropriate use of PPIs, the occurrence of potential side effects and the increase in healthcare costs.

Omeprazole was developed in 1979 and has been on the WHO list of essential medication. ${ }^{21}$ Our analysis found that omeprazole was commonly prescribed, especially among those aged $>65$ years, which was similar to the findings of one study in New Zealand. ${ }^{22}$ Also, prescription preferences on omeprazole have been reflected in pharmacoepidemiological studies conducted in Scotland, New Zealand and Australia. ${ }^{22-24}$ Despite omeprazole, rabeprazole and pantoprazole being among the most frequently prescribed drugs in our study, at present, at least five available PPIs including esomeprazole, lansoprazole, omeprazole, pantoprazole and rabeprazole are mainly prescribed for patient care. So, clinicians should choose the most appropriate PPIs according to different pharmacokinetic characteristics, tissue selectivity, binding specificity and potential interaction with the cytochrome P450 enzyme system. Meanwhile, we observed that more than half of new users $(59 \%)$ had only one dispensing. The average number of dispensing was 1.8 , and a little bit higher than that value from a nationwide PPI utilisation study in France. ${ }^{25}$ However, the mean treatment duration was significantly lower (23 days vs 41 days). The proportion of patients with prolonged ( $>6$ months) PPI therapy accounted for only $0.4 \%$ of new users overall, and $1.0 \%$ of those were aged over 65 years. The result is also comparable with the finding of a study in France. These results present a relatively low frequency and short treatment duration, which may be necessary to avoid PPI overuse, potentially serious adverse events and costly PPI treatment.

Despite several guidelines and many published reports highlighting the importance of appropriate use of PPIs and potential drawbacks of inappropriateness, the inappropriate use of PPI remained in clinical practice. For instance, Giannini $e t a l^{26}$ reported that PPIs were inappropriately used in about $40 \%$ of outpatients, and an even higher inappropriate rate of PPIs was found in $68.8 \%$ of patients by Thomas et al. ${ }^{27}$ In our study, PPIs are inappropriately prescribed in around $50 \%$ of prescriptions. Although the indications for PPI use have expanded, the PPI prescriptions used for inappropriate indications were very common, ${ }^{2}$ which also could be reflected in a study conducted in more than 45 hospitals in China. ${ }^{21}$ These facts alert the increasing worries regarding the cost and also safety, especially for long-term use.

Clinical diagnosis is the foundation in support of prescribing appropriate medication to initiate certain therapy. In our survey, the overall approved indication prescription ratio does not exceed $50 \%$; for instance, the prescription for $H$. pylori eradication accounted for $34 \%$. Of note, the prescription for gastritis-related diagnosis accounted for $34 \%$ among all prescriptions and is similar to Jie Ying's survey result (34.3\%) among 45 hospitals in China. ${ }^{20}$ Gastritis-related diagnosis is a vague diagnostic description or symptom and is classified as an uncertain indication for PPI use. The PPI was mostly prescribed in the departments of gastroenterology in our study, which could result from the main application of PPI in digestive system diseases. Unfortunately, we could not rule out unreasonable PPI use in gastritis-related diagnosis due to the deficiency and information shortage in our electronic medical records. Therefore, we should strengthen the training of doctors in diagnosis and prescriptions, and reciprocal correspondence between diagnosis and medication to achieve improved diagnostic validity and avoid overuse of PPIs.

GC use can lead to adverse reactions, such as PUD. In addition, other debated potential adverse reactions are also frequently reported. ${ }^{28}$ However, the occurrence of such adverse reactions is often associated with higher dosages or long-term use. In our study, PPIs were frequently used in co-prescription with GCs ( $\mathrm{n}=314$, $50 \%$ ), but patients with measurable risk factors that would support the use of a gastroprotective therapy accounted for only $24 \%$. Despite the previous studies showing that patients get no additional benefit from PPI prophylaxis by taking systemic GCs without concomitant NSAIDs, ${ }^{29}{ }^{30}$ GCs are still considered as a cause of upper GI complications by many prescribers who systematically add PPIs to their prescriptions. ${ }^{31}$ The occurrence may be also reflected in our result where the risk of GI bleeding was low, but PPI usage was frequently identified. Clinicians should assess the risk factors of bleeding, such as age, whether there was concomitant use of NSAIDs and whether PPIs were used as gastric mucosal protective agents when prescribing glucocorticoids, instead of using PPI combination therapy once glucocorticoids alone are used.

NSAIDs are very effective for the management of pain by various inflammatory conditions and among the most widely prescribed medications. However, a large number of adverse events in the GI tract, particularly in the gastric mucosa, were reported. In our study, only $14 \%$ of new users with co-prescription initiated an NSAID therapy and $43 \%$ of them with a measurable risk factor of GI complications. This proportion was lower than the result from Marion Lassalle et als research $(53.5 \%)$, in which $80 \%$ of PPI new users had co-prescription with NSAIDs without any measurable risk factor. ${ }^{25}$ About half of the patients in this study did not have high-risk factors but used PPI to prevent NSAID-related ulcers. However, it is not recommended to use gastroprotective strategies with PPIs in younger NSAID users ( $<65$ years) and without other known risk factors, and this is also one of the main causes of NSAID misuse. ${ }^{32}$ Therefore, clinicians should be trained and guided on the exact indications of PPI to reduce unnecessary use of PPI and avoid serious adverse reactions.

Unexpectedly, we found that omeprazole was mainly prescribed with antiplatelet in our study. Omeprazole 
is metabolised mainly through CYP2C19, which may interact with other drugs that are metabolically activated by the same enzyme such as clopidogrel. So, omeprazole could lead to the reduced protective role of clopidogrel in cardiovascular events. In March 2010, The Food and Drug Administration (FDA) issued a 'black box warning' to warn that the prescription on clopidogrel should avoid concomitant use of omeprazole or esomeprazole if the patients have been identified as CYP2C19 poor metabolisers, ${ }^{33}$ especially in East-Asian patients for whom the CYP2C19 loss-of-function (LoF) allele is associated with an increased risk of adverse cardiovascular outcomes when treated with clopidogrel. ${ }^{19}$ In this case, lansoprazole and pantoprazole could be considered as a rational choice. $^{34}$

In terms of cost-effective prescribing, the DDC results showed that the highest average daily costs of PPIs were injectable omeprazole, followed by oral esomeprazole. Thus, the result indicated that these patients paid a higher price when these drugs were prescribed. The lowest DDC value was for oral lansoprazole, suggesting that it has a price advantage for therapy. However, lansoprazole was one of the least used oral PPIs in our study. Meanwhile, despite oral esomeprazole, the DUI value of all forms PPIs was above 1 , and the highest DUI value was 1.8 for pantoprazole and showed that PPI dose was excessive. As mentioned previously, pantoprazole is the most commonly used in the approved indications, indicating that the overdose use of this type of PPIs should be strictly managed in the future.

A Canadian population study has shown that highdose PPI use is becoming more prevalent. ${ }^{35}$ In our study, we found that high-dose therapy was most frequently prescribed $(73 \%)$ compared with standard $(23 \%)$ and low-dose therapy (3.6\%), which was similar to the findings of the result in Australia in $2017^{16}$ but higher than other studies. ${ }^{12}$ The effect of dose and type of PPI research has shown that high doses of PPIs could increase the risk of chronic kidney disease at an impressive level (92\%) for any kind of PPI exposure, and this risk increased even more when doing the follow-up. ${ }^{36}$ There are pieces of evidence to suggest that high-dose PPIs can lead to the development of hypomagnesemia, ${ }^{37}$ and increase the risk of osteoporotic fractures $^{38}$ and serious cardiovascular disease. ${ }^{39}$ Furthermore, it also increased the risk of iron deficiency in renal transplant recipients, ${ }^{40}$ and even 1-year mortality in older inpatients needed acute care. ${ }^{41}$ In daily clinical practice, the common PPI dose may be doubled when common-dose PPIs cannot control and alleviate symptoms. Thus, once symptoms were adequately relieved, a 'step down' therapy is recommended to reduce the dose to the lowest effective dose through a periodic reassessment of patients. ${ }^{12} 42$ Together, these collective shreds of evidence highlight the importance of doctors in collaborative practices with supervisor pharmacists to develop innovative practices to provide economic, effective and safe pharmacotherapy.

Although our study found some characteristics of PPI utilisation and pointed out irrational drug prescribing, our study also has several limitations. First, the data in our article were obtained from just one hospital and did not include the data from the private healthcare and community hospitals. Although the number of patients included is estimated to be relatively small, it also reflects the trends in PPI usage and general problems in clinical practice. Second, the conclusion was based on an observational study, and a further randomised clinical trial may be needed to provide causative explanations. Third, the actual prevalence of PPIs may be underestimated because the information on over-the-counter drugs was lacking. Thus, we suggest future studies should be conducted with a longitudinal cohort design based on more rigorous standards for initial, randomised clinical trials and ongoing follow-up to provide more extensive investigation and more convincing effective therapy.

\section{CONCLUSION}

The results of this study showed that PPI utilisation was accompanied by unapproved indications and excessive dosages. There was a lack of indication for combined medication. Inappropriate co-prescription with GCs was frequent. So, overuse of PPIs and the high rate of inappropriate prescriptions reflect a lack of concern for optimising PPI use. Efforts should be made to limit PPI treatments to appropriate indications and ensure the choice of suitable PPIs promoting rational use. The educational activities would be useful to address concerns of PPI indication, adverse effects and novel indication. Healthcare practitioners should assess the risk and benefit while prescribing the PPIs to identify the actual need and to choose the most rational alternative.

Contributors $\mathrm{YL}$ and $\mathrm{JZ}$ conceived and designed the study. $\mathrm{YL}, \mathrm{XZ}$ and RL analysed the data and drafted the manuscript. YL and JZ collected and organised the patient data. FZ critically revised the manuscript. All authors read and approved the final manuscript.

Funding The work was funded by the Key Construction Project on Clinical Pharmacy (1229).

Disclaimer The funding sources had no involvement in study design; in the collection, analysis and interpretation of data; in the writing of the report; or in the decision to submit the article for publication.

Competing interests None declared.

Patient consent for publication Not required.

Ethics approval Ethical approval was not required for this study. The present study retrospectively analysed data abstracted from the hospital information system of Jinshan Hospital without interventions or disruptions to patients' lives, and no direct human participants were involved, thus informed consent was not required and waived by the Ethics Committee of Jinshan Hospital Affiliated to Fudan University.

Provenance and peer review Not commissioned; externally peer reviewed.

Data availability statement No data are available.

Supplemental material This content has been supplied by the author(s). It has not been vetted by BMJ Publishing Group Limited (BMJ) and may not have been peer-reviewed. Any opinions or recommendations discussed are solely those of the author(s) and are not endorsed by BMJ. BMJ disclaims all liability and responsibility arising from any reliance placed on the content. Where the content includes any translated material, BMJ does not warrant the accuracy and reliability of the translations (including but not limited to local regulations, clinical guidelines, 
terminology, drug names and drug dosages), and is not responsible for any error and/or omissions arising from translation and adaptation or otherwise.

Open access This is an open access article distributed in accordance with the Creative Commons Attribution Non Commercial (CC BY-NC 4.0) license, which permits others to distribute, remix, adapt, build upon this work non-commercially, and license their derivative works on different terms, provided the original work is properly cited, appropriate credit is given, any changes made indicated, and the use is non-commercial. See: http://creativecommons.org/licenses/by-nc/4.0/.

ORCID iD

Yujuan Liu http://orcid.org/0000-0002-1172-4886

\section{REFERENCES}

1 Strand DS, Kim D, Peura DA. 25 years of proton pump inhibitors: a comprehensive review. Gut Liver 2017;11:27-37.

2 Forgacs I, Loganayagam A. Overprescribing proton pump inhibitors. BMJ 2008;336:2-3.

3 NHS Digital. Prescription Cost Analysis England 2018, Prescribing \& Medicines Team, NHS Digital Responsible Statistician: Ian Bullard. Available: https://digital.nhs.uk/data-and-information/publications/ statistical/prescription-cost-analysis/2018

4 Zeng W, Finlayson AE, Shankar S, et al. Prescribing efficiency of proton pump inhibitors in China: influence and future directions. BMC Health Serv Res 2015;15:11.

5 Heidelbaugh JJ, Kim AH, Chang R, et al. Overutilization of protonpump inhibitors: what the clinician needs to know. Therap Adv Gastroenterol 2012;5:219-32.

6 Sattayalertyanyong O, Thitilertdecha P, Auesomwang C. The inappropriate use of proton pump inhibitors during admission and after discharge: a prospective cross-sectional study. Int J Clin Pharm 2020;42:174-83.

7 Corsonello A, Lattanzio F. Cardiovascular and non-cardiovascular concerns with proton pump inhibitors: are they safe? Trends Cardiovasc Med 2019;29:353-60.

8 Yu L-Y, Sun L-N, Zhang X-H, et al. A review of the novel application and potential adverse effects of proton pump inhibitors. Adv Ther 2017;34:1070-86.

9 Appaneal HJ, Caffrey AR, Beganovic M, et al. Predictors of Clostridioides difficile recurrence across a national cohort of veterans in outpatient, acute, and long-term care settings. Am J Health Syst Pharm 2019;76:581-90.

10 van der Hoorn MMC, Tett SE, de Vries OJ, et al. The effect of dose and type of proton pump inhibitor use on risk of fractures and osteoporosis treatment in older Australian women: a prospective cohort study. Bone 2015;81:675-82.

11 Shiraev TP, Bullen A. Proton pump inhibitors and cardiovascular events: a systematic review. Heart Lung Circ 2018;27:443-50.

12 Hendrix I, Page AT, Korhonen MJ, et al. Patterns of high-dose and long-term proton pump inhibitor use: a cross-sectional study in six South Australian residential aged care services. Drugs Real World Outcomes 2019;6:105-13.

13 Association CP. Expert consensus on optimal application of PPIs. Chin J Hosp Pharm 2020.

14 Editorial Board of Chinese Journal of Geriatrics CMA. Expert consensus on the rational use of proton pump inhibitors in the elderly in China. Chin J Geriatr 2015;34:1045-52.

15 Kelly OB, Dillane C, Patchett SE, et al. The inappropriate prescription of oral proton pump inhibitors in the hospital setting: a prospective cross-sectional study. Dig Dis Sci 2015:60:2280-6.

16 Yu S-Y, Lee B, McGuire TM, et al. Consumption of medicines used for gastric acid-related disorders in Australia and South Korea: a cross-country comparison. Eur J Clin Pharmacol 2020;76:547-55.

17 Jarbøl DE, Lykkegaard J, Hansen JM, et al. Prescribing of protonpump inhibitors: auditing the management and reasons for prescribing in Danish general practice. Fam Pract 2019;36:758-64.

18 Gamelas V, Salvado V, Dias L. Prescription pattern of proton pump inhibitors at hospital admission and discharge. GE Port $J$ Gastroenterol 2019;26:114-20.

19 Zou D, Goh K-L. East Asian perspective on the interaction between proton pump inhibitors and clopidogrel. J Gastroenterol Hepatol 2017;32:1152-9.

20 Ying J, Li L-C, Wu C-Y, et al. The status of proton pump inhibitor use: a prescription survey of 45 hospitals in China. Rev Esp Enferm Dig 2019;111:738-43.
21 World Health Organization. WHO model list of essential medicines 20th edition. Available: http://www.who.int/medicines/publications/ essentialmedicines/en/ [Accessed 17 Jan 2019].

22 Nishtala PS, Soo L. Proton pump inhibitors utilisation in older people in New Zealand from 2005 to 2013. Intern Med J 2015;45:624-9.

23 Bennie M, Godman B, Bishop I, et al. Multiple initiatives continue to enhance the prescribing efficiency for the proton pump inhibitors and statins in Scotland. Expert Rev Pharmacoecon Outcomes Res 2012;12:125-30.

24 Hollingworth S, Duncan EL, Martin JH. Marked increase in proton pump inhibitors use in Australia. Pharmacoepidemiol Drug Saf 2010;19:1019-24.

25 Lassalle M, Le Tri T, Bardou M, et al. Use of proton pump inhibitors in adults in France: a nationwide drug utilization study. Eur $\mathrm{J}$ Clin Pharmacol 2020;76:449-57.

26 Giannini EG, Crespi M, Djahandideh A, et al. Appropriateness of proton pump inhibitors treatment in clinical practice: prospective evaluation in outpatients and perspective assessment of drug optimisation. Dig Liver Dis 2020;52:862-8.

27 Thomas L, Culley EJ, Gladowski P, et al. Longitudinal analysis of the costs associated with inpatient initiation and subsequent outpatient continuation of proton pump inhibitor therapy for stress ulcer prophylaxis in a large managed care organization. $J$ Manag Care Pharm 2010;16:122-9.

28 Bénard-Laribière A, Pariente A, Pambrun E, et al. Prevalence and prescription patterns of oral glucocorticoids in adults: a retrospective cross-sectional and cohort analysis in France. BMJ Open 2017;7:e015905.

29 Fardet L, Kassar A, Cabane J, et al. Corticosteroid-Induced adverse events in adults: frequency, screening and prevention. Drug Saf 2007;30:861-81.

30 Jones MG, Tsega S, Cho HJ. Inappropriate prescription of proton pump inhibitors in the setting of steroid use: a teachable moment. JAMA Intern Med 2016;176:594-5.

31 Martínek J, Hlavova K, Zavada F, et al. 'A surviving myth'corticosteroids are still considered ulcerogenic by a majority of physicians. Scand J Gastroenterol 2010;45:1156-61.

32 Savarino V, Marabotto E, Zentilin P, et al. Proton pump inhibitors: use and misuse in the clinical setting. Expert Rev Clin Pharmacol 2018;11:1123-34.

33 U.S. Food and Drug Administration. FDA drug safety communication reduced effectiveness of Plavix (clopidogrel) in patients who are poor metabolizers of the drug. Available: http://www.fda.gov/Drugs/ DrugSafety/Postmarket

34 Pang J, Wu Q, Zhang Z, et al. Efficacy and safety of clopidogrel only vs. clopidogrel added proton pump inhibitors in the treatment of patients with coronary heart disease after percutaneous coronary intervention: a systematic review and meta-analysis. Int $J$ Cardiol Heart Vasc 2019;23:100317.

35 Targownik LE, Metge C, Roos L, et al. The prevalence of and the clinical and demographic characteristics associated with high-intensity proton pump inhibitor use. Am J Gastroenterol 2007;102:942-50.

36 Rodríguez-Poncelas A, Barceló MA, Saez M, et al. Duration and dosing of proton pump inhibitors associated with high incidence of chronic kidney disease in population-based cohort. PLOS One 2018:13:e0204231.

37 Srinutta T, Chewcharat A, Takkavatakarn K, et al. Proton pump inhibitors and hypomagnesemia: a meta-analysis of observational studies. Medicine 2019;98:e17788.

38 Earnshaw SR, Scheiman J, Fendrick AM, et al. Cost-utility of aspirin and proton pump inhibitors for primary prevention. Arch Intern Med 2011;171:218-25.

39 Ray WA, Murray KT, Griffin MR, et al. Outcomes with concurrent use of clopidogrel and proton-pump inhibitors: a cohort study. Ann Intern Med 2010;152:337-45.

40 Douwes RM, Gomes-Neto AW, Eisenga MF, et al. Chronic use of proton-pump inhibitors and iron status in renal transplant recipients. $J$ Clin Med 2019;8.

41 Maggio M, Corsonello A, Ceda GP, et al. Proton pump inhibitors and risk of 1-year mortality and rehospitalization in older patients discharged from acute care hospitals. JAMA Intern Med 2013;173:518-23.

42 Othman F, Card TR, Crooks CJ. Proton pump inhibitor prescribing patterns in the UK: a primary care database study. Pharmacoepidemiol Drug Saf 2016;25:1079-87. 